\title{
457 実稼動データを用いた伝達寄与分析の検討
}

\section{Investigation of Transfer Path Analysis based on Operational Analysis}

\author{
○学 福島 佑輔 （首都大学東京大学院） 正 吉村 卓也 (首都大学東京) \\ Yusuke Fukushima, Tokyo Metropolitan University, 1-1 Minamiosawa, Hachioji-city, Tokyo \\ Takuya Yoshimura, Tokyo Metropolitan University
}

\begin{abstract}
Transfer Path Analysis (TPA) is frequently used for Noise and Vibration problems especially in vehicle development stage. TPA finds the input and transfer path having the major contribution to the evaluation output. The precision and the easiness of TPA analysis is strongly demanded in order to attain the noise reduction and to shorten the time length of design cycle. Recently, a new TPA technique based on operational analysis and the principal component analysis has been proposed. This paper focuses on the new TPA technique, and the investigation is carried out by comparing the new TPA with the conventional TPA.
\end{abstract}

Key Words: Transfer Path Analysis, Noise and Vibration, Operational Analysis, Principal Component Analysis, Transfer Function

\section{A1. 緒 言}

近年，機械の製品開発においては，振動・騒音問題に対し て, 伝達経路解析 (Transfer Path Analysis 以降 TPA) を 用いた振動・騒音解析が盛んに行われている.これは, 複数 の振動源之振動伝達経路の中から奇与の高いものを見出す 方法であり，機械の低振動·低騒音化を実現し，かつ製品開 発期間を短縮させるために，高い精度が求められている．本 研究では，近年注目されている主成分分析を用いた実稼動デ 一タによる TPA（以下実稼動 TPA）を取り上げ，従来の入 力同定に基づく逆行列法による TPA（以下従来 TPA）との 違いについて検討, 考察する。

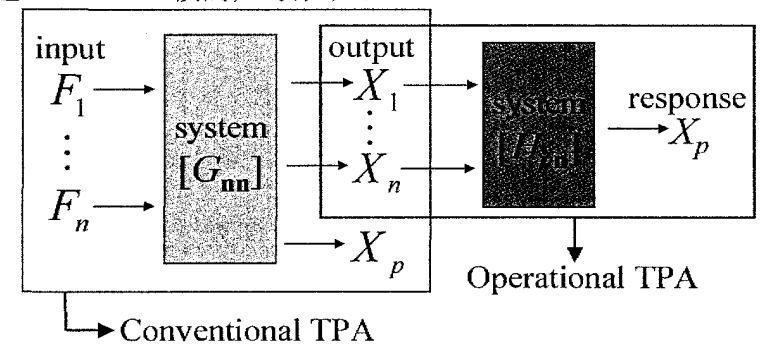

Fig.A1 Concept of Operational TPA and Conventional TPA

\section{A2. 理論説明}

従来TPA と実稼動TPAを比較した概念図を図A1に示す. 従来 TPA では, 次式のように応答を入力と伝達関数 (FRF) の 積の和で表し, 入力寄与の和として忘答を表し評価する.

$$
X_{p}=G_{1} F_{1}+G_{2} F_{2}+\ldots+G_{n} F_{n}
$$
従来の TPA では, FRF 行列 $\left[G_{n n}\right]$ 注振動試験で求め, 実稼 動応答べクトルにこの逆行列老乗ずることにより、入力 $\{F\}$ を推定する.これに振動評価点への FRF を乗ずることで入 力寄与分析老行う.

次に，実稼動 TPA の基本関係式を以下に示す.

$$
X_{p}=H_{1} X_{1}+H_{2} X_{2}+\ldots+H_{n} X_{n}
$$

奏稼動 TPA $の$ 特徵は, 評洒量 $X$, 他の点の振動忘答 (本研 究では加速度とする） $\{X\}$ の重袷わせで表すことであり， 実稼㗢中の加速度応答データに対して主成分分析を利用し て伝達関数 $[H]$ を算出する.この伝達関数を用いて寄与分析 を行うため, 実稼動 TPA では加振実験の必要がなく工数削 減が実現できる。一方，式(A2)見てわかるように、従来 TPA が入力寄与分析であるのに対し, 実稼動 TPA ば 忘答” 寄与分析であるといえる.

\section{A3. 解析的考察}

まず、実稼動 TPAにおける伝達関数 $[H]$ について考察する. これは以下のように，従来 TPAの FRF を用いて表すことが できる.

$\left\lfloor H_{p n}\right\rfloor=\left\lfloor G_{p n}\left\lfloor G_{n n}\right\rfloor^{-1}\right.$

この伝達関数は加速度センサーの貼り付け位置や個数によ って変化はするが，系固有の特性であることが分かる．実稼 動 TPA においてこれが得られるための条件は，各入力が無 相関であること，次式が成り立つことであることが分かった。

(独立な加振力数) $=$ (加速度参照点数)

また，実稼動 TPAによって得られる寄与は，従来 TPA 亡 は本質的に異なるものであるが，参照点間の FRF が以下の条 件の時には，両者が等しい奇与となることを示した。

$$
G_{i j}=0 \quad(i \neq j) \quad \text { (A5) }
$$

この条件は, 加速度参照点を入力点近傍に取った場合で, しかもその点の入力が他の入力点からの影響を受けないよ うな限られた場合であると言える。

$$
\text { A4. シミュレーション }
$$

簡易構造物を対象として, 従来 TPA と実稼動 TPAにより 寄与分析を行い結果を比較した。ここでは等しい大きさを持 つ無相関なランダム入力を構造物上 4 点に与えた場合の寄 与を評価し, その結果 Fig.A2 に示す. 横軸は周波数, 縦軸 は奇与率であり，各周波数における寄与の和が 1 になるよう に正規化して示している.またまた図中では各点からの需与 を異なる色で示している。これを見ると，実稼動 TPA は従 来 TPA とは全般的に異なる結果を示していることが確認で きる.

\section{A5. 結 言}

本研究では, 実稼動 TPA に着目し, 従来 TPA と比較を通 じて雨者の違いを考察した。

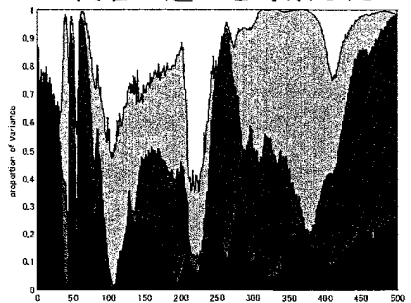

Operational TPA

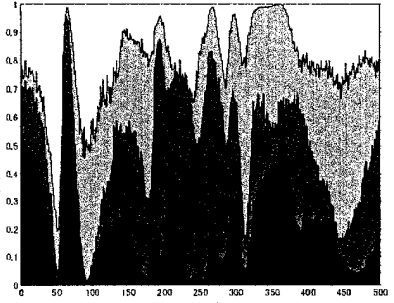

Conventional method
Fig.A2 Comparison of contribution results 


\section{1. 緒 言}

近年，機械の製品開発においては，振動・騒音問題に対し て, 伝達経路解析 (Transfer Path Analysis 以降T P A) を用いた検討が行われており，特に自動車の製品開発におい て広く使われている。これは, 複数の振動源と振動伝達経路 の中から寄与の高いものを見出す方法であり，低振動・低騷 音化を実現し，かつ製品開発期間を短縮させるために，高い 精度が求められている.この TPA としては, 逆行列法, マ ウントスティフネス法などがあるが，伝達関数の事前計画が 必要で労力と時間を要する, 入力同定の精度が十分確保され ない，などの問題点があった，一方最近では，実稼動データ を用いた主成分分析に基づく方法（以下，実稼動 T P A ) が 提案されている。 そこで本研究では，実稼動 TPA 取り上 げ，従来の人力同定に基づく逆行列法による TPA（以下，従 来 TPA）と比較与ることにより，両者の違いを考察する．両 手法の概念図を図 1 に示才。

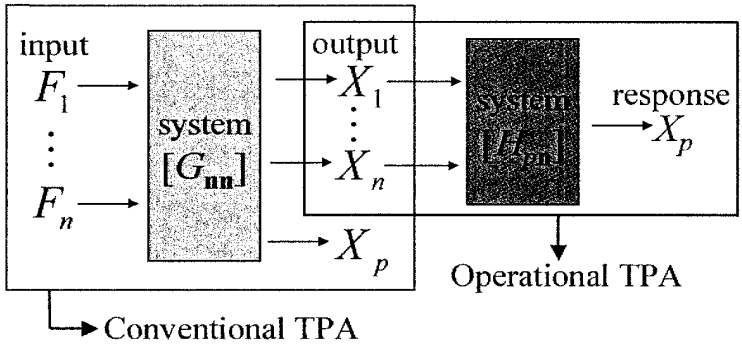

Fig.1 Concept of Operational TPA and Conventional TPA

\section{2. 理論説明}

2. 1 従来TPAについて

構造物上の $n$ 個の点における入出力関係を考えると，

$$
\left\{X_{\mathrm{n}}\right\}=\left[G_{\mathrm{nn}}\right]\left\{F_{\mathrm{n}}\right\}
$$

ただし, 添え字の $\mathbf{n}$ はベクトルまたは行列の大きさが $n$ 次元 であることを表し，

$$
\left\{X_{n}\right\}=\left\{X_{1}, \ldots, X_{n}\right\}^{t},\left\{F_{n}\right\}=\left\{F_{1}, \ldots, F_{n}\right\}^{t}
$$

またこれとは別に出力評価点を $p$ とすると，

$$
X_{p}=\left\lfloor G_{p \mathbf{n}}\right\rfloor\left\{F_{\mathbf{n}}\right\}
$$

$$
こ こ に
$$

$$
\left\lfloor G_{p \mathrm{n}}\right\rfloor=\left\lfloor G_{p 1}, \ldots, G_{p n}\right\rfloor
$$

従来の TPAである逆行列法においては，式(1)より，

$$
\left\{F_{\mathrm{n}}\right\}=\left[G_{\mathrm{nn}}\right]^{-1}\left\{X_{\mathrm{n}}\right\}
$$

として入力を推定し，これにより，

$$
\begin{aligned}
X_{p} & =\left\lfloor G_{p 1}, \cdots, G_{p n}\right\rfloor\left\{F_{\mathrm{n}}\right\} \\
& =G_{p \mathrm{l}} F_{1}+\ldots+G_{p n} F_{n}
\end{aligned}
$$

の上うに，評価点 $p$ における応答を $n$ 個の入力の重称合わ せで表す。ここで, 式(6)の右辺各項が各入力点からの寄与 を表す。ここで, 従来 TPAにおいては, FRF 行列 $\left[G_{n n}\right]$ は事 前の振動試験により計測しておく必要がある。また，式(5) のように FRF 行列の逆行列を用いて入力を推定するが，入 力推定の十分な精度確保が困難であることなどが知られて いる. (※参考文献 $(2)$ )

\section{2 実稼動 TPA について}

尖稼動 TPA では，以下のような関係を考える。

$$
\begin{aligned}
X_{p} & =H_{p 1} X_{1}+, \ldots,+H_{p n} X_{n} \\
& =\left\lfloor H_{p \mathrm{n}}\right\rfloor\left\{X_{\mathrm{n}}\right\}
\end{aligned}
$$

ここで, 右辺に含まれる伝達関数 $\left\lfloor H_{p n}\right\rfloor$ を定めることができ れ状，評価点 $p$ における忘答を振動応答（本研究では加速 度とする $X_{i}(i=1, \ldots, n)$ の重ね合わせによって表すこと ができる.この右辺の各項を各参照点からの寄与とする. 伝 達関数 $\left[H_{p}\right\rfloor$ の決定については, 式(7) を]以下のように表し,

$$
X_{p}=\left\lfloor X_{\mathbf{n}}\right\rfloor\left\{H_{\mathbf{n} p}\right\}
$$

計測を $m$ 回繰り返したとすると，

$$
\{P\}=[X]\left\{H_{\mathrm{n} p}\right\}
$$

ここで,

$$
\begin{gathered}
\{P\}=\left\{X_{p}^{(1)}, \ldots, X_{p}^{(m)}\right\}^{\prime},\left\{H_{\mathrm{n} p}\right\}=\left\{H_{1 p}, \ldots, H_{n p}\right\}^{\prime} \\
{[X]=\left[\begin{array}{ccc}
X_{1}^{(1)} & \cdots & X_{n}^{(1)} \\
\vdots & \ddots & \vdots \\
X_{1}^{(m)} & \cdots & X_{n}^{(m)}
\end{array}\right] \quad(10)}
\end{gathered}
$$

伝達関数 $\left\{H_{\mathrm{n} p}\right\}$ を定めるには，

$$
\left\{H_{\mathrm{n} p}\right\}=[X]^{+}\{P\}
$$

のように擬似逆行列 $[X]^{+}$用いる。ここで擬似逆行列を求 める際に, 行列 $[X]$ の特異值成分は, 振動応答の主成分に対 応するので, 主成分分析を用いた方法として説明されている. $(※$ 参考文献 $(1))$

\section{3. 解析的考察}

\section{1 実稼動 TPA の伝達関数について}

ここでは，実稼動 TPA について解析的に考察する，実稼 動 TPA で定める伝達関数 $\left\{H_{n p}\right\}$ を解析的に表すことを考え る. 式(5)を式(3)に代入することにより,

$$
X_{p}=\left\lfloor G_{p \mathrm{n}}\right\rfloor\left[G_{\mathrm{nn}}\right]^{-i}\left\{X_{\mathrm{n}}\right\}
$$

これと式(7)により，

$$
\left\lfloor H_{p \mathrm{n}}\right\rfloor=\left\lfloor G_{p \mathrm{n}}\right\rfloor\left[G_{\mathrm{nn}}\right]^{-1}
$$

が得られる。これが伝達関数 $\left\{H_{n p}\right\}$ の解析解である.この伝 達関数は加速度センサーの測定位置や個数によって変化は するが，FRF で表されており系固有の特性であることが分 かる。

\section{2 伝達関数の同定条件}

実稼動 TPA で同定する伝達関数は式(13)で表されること が分かるが, 事前の振動試験を実施せずに実稼動状態で同定 することができるための条件を考察した.この条件は, 各入 力が無相関であることと，次式が成り立つことである.

(独立な加振力数) $=$ (参照点数 $n$ )

3. 3 実稼動 TPA と従来 TPA の奇与が等しくなる条件 特別な場合として, 各入力点における応答が他の入力点か らの影響を受忛ない場合を考え， 


$$
G_{i j}=0 \quad(i \neq j)
$$

が成り立つと伖定する。すなわち，

$$
\left[G_{\mathrm{nn}}\right]=\left[\begin{array}{ccc}
G_{11} & & O \\
& \ddots & \\
O & & G_{n m}
\end{array}\right]
$$

$こ \infty$ 时,

$$
\begin{aligned}
& \left\lfloor H_{p \mathbf{n}}\right\rfloor=\left\lfloor G_{p \mathbf{n}}\right\rfloor\left[G_{\mathrm{nn}}\right]^{-1}=\left\lfloor\frac{G_{p 1}}{G_{\| 1}}, \ldots, \frac{G_{p n}}{G_{m}}\right\rfloor \\
& X_{i}=G_{i i} F_{i}
\end{aligned}
$$

が成り立つので,

$$
\begin{aligned}
X_{p} & =H_{p 1} X_{1}+\ldots,+H_{p n} X_{n} \\
& =\frac{G_{p 1}}{G_{11}} G_{11} F_{1}+, \ldots,+\frac{G_{p n}}{G_{m m}} G_{m n} F_{n} \\
& =G_{p 1} F_{1}+, \ldots,+G_{p n} F_{n}
\end{aligned}
$$

となる。このことは, 式(14)が成り立つ時は, 実稼動 TPA と従来 TPA の需与が等しいことを示している. しかしこれ は, 加速度参照点を入力点近傍に取った場合で, しかもその 点が他の入力点からの影響を受けないような非常に限られ た場合であると言える.

$$
\text { 4. シミュレーション }
$$

本章では, 簡易構造物に対して数值シミュレーションを行 うことにより, 実稼動 TPA と従来 TPAを比較する. 自動車の 車室を模した簡易モデルの概略を図 2 に示す。.また，モデル パラメータを表 1 に示す.

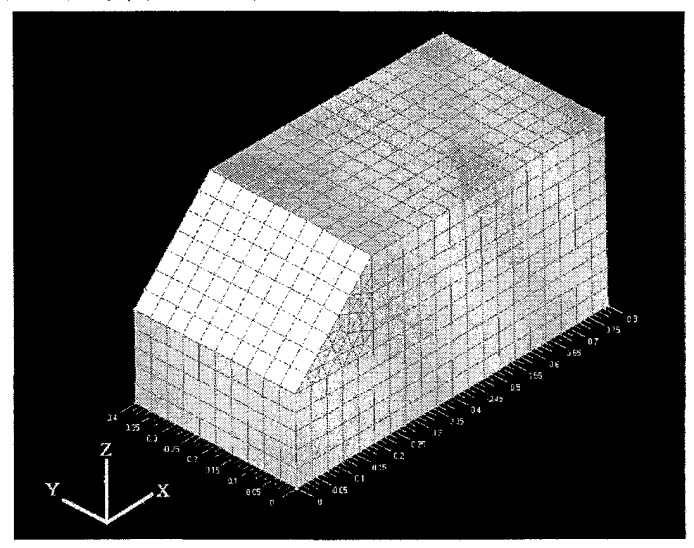

Fig.2 Simulation model

\begin{tabular}{|c|c|c|c|}
\hline size $(\mathrm{m})$ & $\mathrm{X}$ & 0.8 & \multicolumn{2}{|}{} \\
\hline & $\mathrm{Y}$ & 0.4 & \multicolumn{2}{|}{} \\
\hline & $\mathrm{Z}$ & 0.4 & \multicolumn{1}{|c|}{} \\
\hline & material & thickness(m) & $\begin{array}{l}\text { Young' } \\
\text { modulus(GPa) }\end{array}$ \\
\hline front panel & Duralumin & 0.02 & 71 \\
\hline side panel & Duralumin & 0.005 & 71 \\
\hline back panel & Steel & 0.003 & 207 \\
\hline upper panel & Steel & 0.003 & 207 \\
\hline floor panel & Steel & 0.003 & 207 \\
\hline
\end{tabular}

Table.1 Model detail

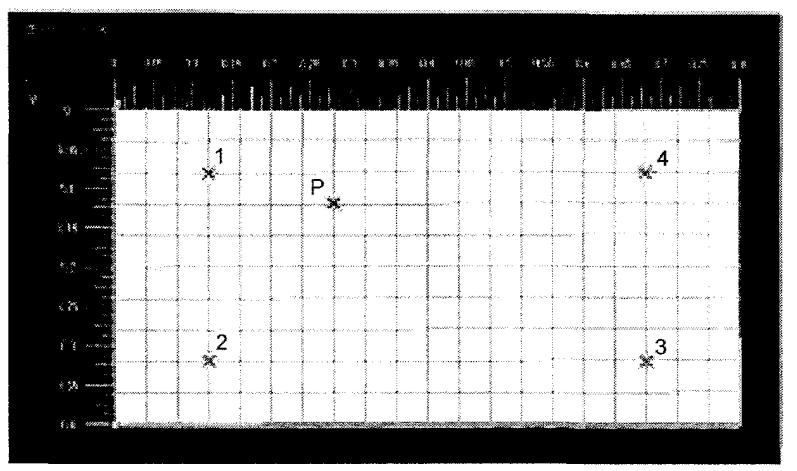

Fig.3 Bottom view of the floor panel

図 1 のモデルは，底面 4 ケ所をばね支持されており，ばね 取り付け点モデル側の 4 点を加振し，その点を加速度参照点 とする，また，応答評価点は，底面やや中央よりのフロア振 動としている. 4 点の加振点ならびに加速度参照点（点 1 〜 点 4) と応答評価点 (点 $P$ ) 省示している. また, 加振力は 正規分布に従うランダム入力とし，4点無相関ランダム加振 とした.

実稼動 TPA では計測回数を $\mathrm{m}=100$ として, 以下のシミ ュレーションを実行した.

\section{1 同定条件の検証}

本シミュレーションの条件は, (独立な加振力数=加速度参 照点）を満足している.この時, 実稼動 TPAによって得ら れた伝達関数が解析的に導かれるもの（式(13)）と等しいこ とを確認した. 図 4 は加速度参照点 1 と忘答評価点 $P$ の間の 伝達関数 $\left(H_{p 1}\right)$ である.ここで, 理論的に導かれた伝達関数 が実稼動 TPA で得られた結果と良く一致していることが確 認できる。このことから, 系固有の伝達関数が実稼動 TPA によって同定されており,他の点の伝達関数においても一致 していることを確認した。
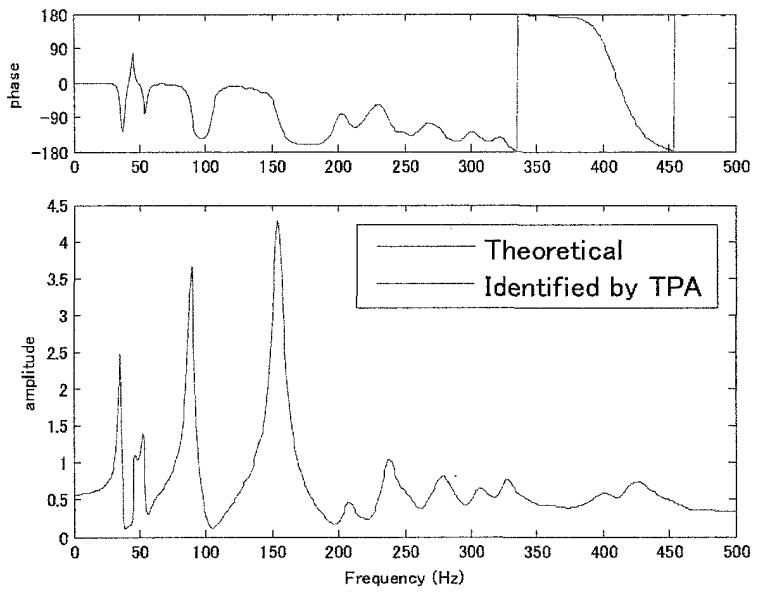

Fig. 4 Transfer function $H_{p 1}$

4. 2 実稼動 TPA と従来 TPA の結果比較

ここでは，両方法による寄与分析の結果を比較する。いず れの方法においても，伝達関数と参照データの積の和で表さ れる. 実稼動 TPAにおいては, 伝達関数 $\mid H\rfloor$ を決定した後 に, 評価点応答の寄与を求め, そのパワースペクトルを計測 回数分だけ平均化することにより，応答の奇与を算出した。 すなわち, 


$$
S_{p i}=\frac{1}{m} \sum_{k=1}^{m}\left|H_{p i} X_{i}^{(k)}\right|^{2}
$$

ここで， $S_{p i}$ は評俩点 $p$ における $i$ 点入力による応答平均パ ワースペクトル $\left[\mathrm{m}^{2} / \mathrm{s}^{5}\right]$ である。シミュレーションは以下の 3 条件で実施した。

条件 $1=4$ 点のランダム人力の大きさが等しい

$$
\left(\sigma_{1}=\ldots=\sigma_{4}=1\right)
$$

条件 2 二点 3 の加振力のみ 10 倍の大きさを持つ。

$$
\left(\sigma_{1}=10, \sigma_{2}=\sigma_{3}=\sigma_{4}=1\right)
$$

条件 3 =入力は条件 1 に同じ． 4 筒所の加振点近傍の板厚 を 10 分の 1 に変更.

また，得られた寄与については，各周波数における寄与の和 が 1 になるように正規化して示すこととする.

\section{2.1 「条件 1 」の結果}

条件 1 での寄与分析の結果を図 5 に示す．グラフは，下か ら順に, 点 1 , 点 2 , 点 3 , 点 4 , の寄与を割合で表してい る．対象周波数は，0〜 $500 \mathrm{~Hz}$ である．結果省ると，周波数 全体にわたる寄与の傾向としては, 類似はあるものの定量的 には異なったものであることが確認できる。

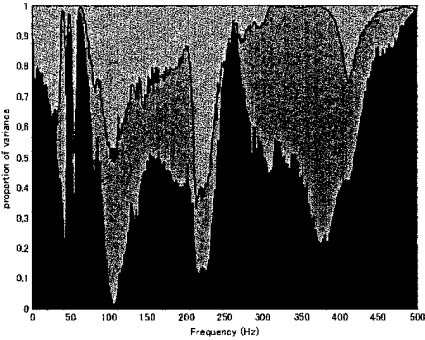

Operational TPA

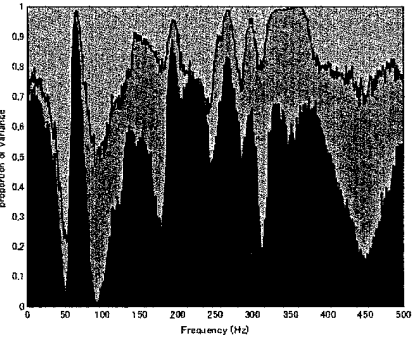

Inversion matrix method
Fig. 5 Contribution ratio

\subsection{2 「条件 2 」結果}

条件 2 での奇与分析の結果を図 6 に示寸，従来 TPA では 入力点 3 の寄与が最も大きくなっていることが確認できる. 実稼動 TPA においては点 3 の寄与がやや大きくなっている ものの，従来 TPA とはことなる傾向を示していることがわ かる.

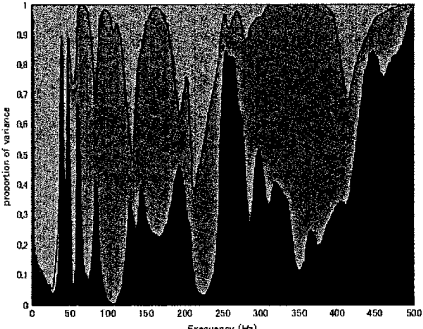

Operational TPA

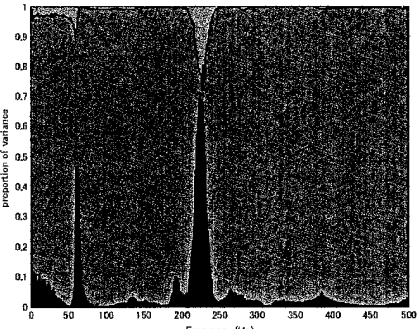

Inversion matrix method
Fig.6 Contribution ratio

\section{2, 3 「条件 3 」の結果}

最後に, 4 箅所の加振点の周りの板厚を $3 \mathrm{~mm}$ から 10 分 の 1 の. $3 \mathrm{~mm}$ に変更した。 モデル底面を図 7 に示す。こ の図で 4 箅所の緑色の部分が板厚を変更した領域である。ま た寄与分析の結果を図 8 に示す。

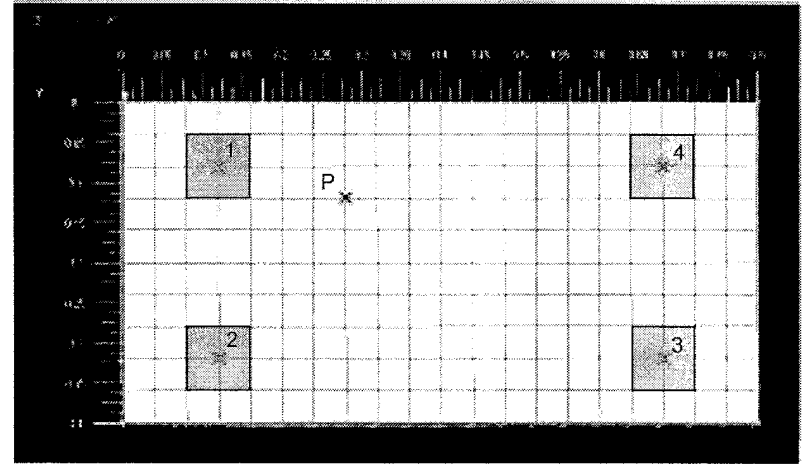

Fig.7 Bottom view of the partial thin floor panel

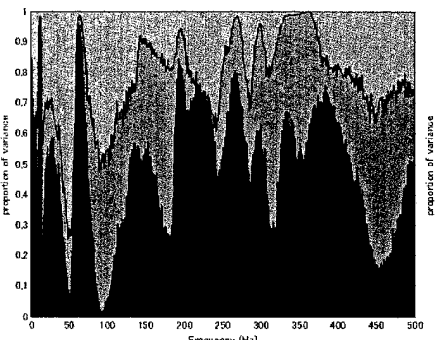

Operational TPA

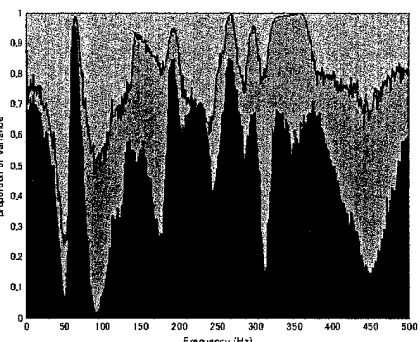

Inversion matrix method
Fig. 8 Contribution ratio

図7を見ると、これまでの比較において最も傾向の近い結 果走していることがわかる.この例では取り付け点の剛性 を低下させることで，両者の結果が一致する条件である，式 (14) $\left(G_{i j}=0(i \neq j)\right)$ に近い条件が成立するものと推測さ れる.この結果から, 加速度参照点の動きがある一つの入力 に支配される時に，従来 TPA と同等の㟢与分析結果を示す 可能性を示唆しているものと考えられる.

\section{5. 結 言}

本研究では，以下の項目について検討，考察した。

1]実稼動 TPA と従来 TPA（逆行列法による TPA）の寄与分 析の相違点

2]実稼動 TPA で求められる伝達関数 $L H\rfloor$ 解析解とその同 定条件

3]実稼動 TPA が従来 TPA と同等の寄与分析結果を示寸条件

またシミュレーションによる検討を行うことにより，上 記の項目内容について確認した。

\section{謝 辞}

本研究を遂行するにあたり，日産自動車株式会社の丸山新 一氏からは, 有意義なディスカッションと示唆に富んだアド バイスをいただいた。ここに厚く御礼申し上げる.

\section{参考文献}

(1) Kousuke Noumura, Junji Yoshida, Method of Transfer Path Analysis for Interior Vehicle Sound by Actual Measurement Date, 2006 JSAE Annual Congress(Spring),Proceedings 2006-55-06,p.5-12

(2) P.J.G. van der Linden, Comparing inverse force identification and the mount-stiffness force identification methods for noise contribution analysis, ISMA 2004 Conference Proceedings, pp.2971-2986 
(3) H. Van der Auweraer, P. Mas, S. Dom, A. Vecchio, K. Janssens, P. Van de Ponseele, Transfer Path Analysis in the Critical Path of Vehicle Refinement: The Role of Fast, Hybrid and Operational Path Analysis, SAE Noise and Vibration Conference 2007 Conference Proceedings, 2007-01-2352 